\title{
1-Hydroxy-1-norresistomycin, a New Cytotoxic Compound from a Marine Actinomycete, Streptomyces chibaensis $\operatorname{AUBN}_{1} / 7^{\dagger}$
}

\author{
Adinarayana Gorajana, Bapiraju V. V. S. N. Kurada, Sujatha Peela, Premkumar \\ Jangam, Saisha Vinjamuri, Ellaiah Poluri, Axel Zeeck
}

Received: December 2, 2004 / Accepted: August 2, 2005

(C) Japan Antibiotics Research Association

\begin{abstract}
In our systematic screening programme for marine actinomycetes, a bioactive streptomycete was isolated from marine sediment samples of the Bay of Bengal, India. The isolate yielded a new cytotoxic compound. This was obtained by solvent extraction followed by chromatographic purification. The pure compound was identified from spectroscopic data as a quinone-related antibiotic, 1-hydroxy-1-norresistomycin (1). It showed a potent cytotoxic activity against cell lines viz. HMO2 (gastric adenocarcinoma) and HePG2 (hepatic carcinoma) in vitro. It also exhibited antibacterial activities against Gram-positive and Gram-negative bacteria.
\end{abstract}

Keywords Streptomyces, cytotoxic activity, antibacterial activity, quinone, 1-hydroxy-1-norresistomycin

Marine actinomycetes remain an important source in the search for novel bioactive compounds. So far terrestrial substrates have been predominantly exploited as sources of actinomycetes, where as the marine habitat has received much less attention. There are a few reports on bioactive compounds from marine actinomycetes in recent times $[1 \sim 6]$. The marine environment may be an important source of novel anti-cancer, anti-viral, antibacterial and antifungal antibiotics as well as industrially important

E. Poluri (Corresponding author), A. Gorajana, B. V.V.S.N. Kurada, S. Peela, P. Jangam, S. Vinjamuri: Biotechnology Division, Dept. of Pharmaceutical Sciences, Andhra University, Visakhapatnam 530003, India, E-mail: ellaiah2@rediffmail.com

A. Zeeck: Institut fur Organische Chemie, George-August enzymes.

Taxonomic characteristics of the isolate were determined by cultivation on various media as described by Shirling and Gottlieb [7], Waksman [8] and Arai [9]. Cell wall composition was analyzed by the method of Lechevalier and Lechevalier [10], using thin layer chromatography plates as described by Staneck and Roberts [11]. The taxonomic studies indicated that the isolate belongs to Streptomyces chibaensis and it was designated as $S$. chibaensis $\mathrm{AUBN}_{1} / 7$.

The cytotoxicities of $\mathbf{1}$ were assessed based on their effects on the growth of tumor cells in vitro according to the NCI guide lines [12]. The cell lines used were HMO2 (gastric adenocarcinoma) and HePG2 (hepatic carcinoma). Cells were grown in 96-well microtitre plates of RPMI 1640 tissue culture medium supplemented with $10 \%$ fetal calf serum at $37^{\circ} \mathrm{C}$ in a humidified atmosphere of $50 \% \mathrm{CO}_{2}$ in air. After 24 hours of incubation $1(0.1 \sim 10.0 \mu \mathrm{g} / \mathrm{ml})$ was added to the cells. After 48 hours incubation, the cells were fixed by addition of trichloracetic acid and cell protein was assayed with sulforhodamine B [13]. For each concentration tested, the $\mathrm{GI}_{50}$ (drug concentration causing $50 \%$ growth inhibition), TGI values (drug concentration causing $100 \%$ growth inhibition) and $\mathrm{LC}_{50}$ (minimum concentration which reduces the initial cell number to half) were determined (Table 2).

A full grown slant culture of the strain $\mathrm{AUBN}_{1} / 7$ on

Universitat, Tammannstrasse 2, D-37077, Goettingen, Germany

${ }^{\dagger}$ The same compound (1-hydroxy-1-norresistomycin) which was isolated independently from different strains appears in this issue (pages 530-534). 
starch casein agar (composition: soluble starch 1.0\%, casein $0.03 \%, \mathrm{KNO}_{3} 0.2 \%, \mathrm{NaCl} 0.2 \%, \mathrm{~K}_{2} \mathrm{HPO}_{4} 0.005 \%$, $\mathrm{CaCO}_{3} 0.002 \%, \mathrm{FeSO}_{4} \cdot 7 \mathrm{H}_{2} \mathrm{O} 0.001 \%$, and agar $2.0 \%$ ) was transferred into Erlenmeyer flasks $(2 \times 250 \mathrm{ml})$ containing $50 \mathrm{ml}$ of seed medium (composition: soyabean meal 1.0\%, cornsteep solids $1.0 \%$, glucose $0.5 \%$ and $\mathrm{CaCO}_{3} 0.5 \%$ with $\mathrm{pH} 7.0$ ) and incubated for 2 days at $28^{\circ} \mathrm{C}$ on a rotary shaker $(220 \mathrm{rpm})$.This culture was transferred as a $10 \%(\mathrm{v} / \mathrm{v})$ inoculum into $200 \mathrm{ml}$ aliquots of the production medium contained in $30 \times 1$ litre EM flasks. The medium composition was: soyabean meal $1.0 \%$, corn steep solids $0.5 \%$, soluble starch $1.0 \%$, glucose $0.5 \%$ and $\mathrm{CaCO}_{3} 0.7 \%$ with $\mathrm{pH}$ 7.0. The inoculated production flasks were incubated for 56 hours at $28^{\circ} \mathrm{C}$ on a rotary shaker (220 rpm).

The culture broth (6 litres) was centrifuged at $4000 \mathrm{rpm}$ for 10 minutes, at $10^{\circ} \mathrm{C}$ and clear culture supernatant was separated. It was extracted twice with ethyl acetate $(2 \times 1.2$ litres) and washed with $500 \mathrm{ml}$ water at $\mathrm{pH} 7.0$. The ethyl acetate layer was concentrated in vacuum at $35^{\circ} \mathrm{C}$ to give $5.0 \mathrm{~g}$ of the crude ethyl acetate extract. A polymer was obtained from the crude ethyl acetate extract, which did not possess any antimicrobial activity. The mycelium was extracted with acetone (1.0 litre) and then centrifuged

Table 1 A comparison of ${ }^{13} \mathrm{C}-\mathrm{NMR}$ data of 1-hydroxy-1norresistomycin (1) and resistomycin (2)

\begin{tabular}{lrc}
\hline Carbon & Compound (2) & Compound (1) \\
\hline C-1 & 45.9 & 74.1 \\
C-2 & 204.6 & 204.3 \\
C-2a & 102.5 & 102.5 \\
C-3 & 170.2 & 169.9 \\
C-4 & 100.1 & 100.3 \\
C-5 & 169.7 & 169.7 \\
C-5a & 105.7 & 106.3 \\
C-6 & 184.5 & 184.7 \\
C-6a & 106.4 & 107.0 \\
C-7 & 167.9 & 168.2 \\
C-8 & 119.2 & 119.4 \\
C-9 & 151.5 & 152.5 \\
C-9a & 114.1 & 115.0 \\
C-10 & 162.3 & 160.4 \\
C-11 & 109.5 & 110.2 \\
C-11a & 152.2 & 152.3 \\
C-11b & 107.4 & 106.9 \\
C-11c & 139.5 & 139.2 \\
C-11d & 128.5 & 129.0 \\
C-12 (ax) & 28.4 & 33.3 \\
C-13 (eq) & 28.4 & -8 \\
C-14 & 25.4 & \\
\hline & & \\
\hline
\end{tabular}

(4000 rpm, 10 minutes, $10^{\circ} \mathrm{C}$ ). The acetone extract was concentrated in vacuum and lyophilized to obtain $4.5 \mathrm{~g}$ of mycelium extract.

The mycelium extract ( $4.5 \mathrm{~g})$ was chromatographed on a silica gel column $(22 \times 5 \mathrm{~cm})$ and eluted with dichloromethane/methanol $(95: 5,1$ litre) to give ten fractions. The dried residues of all 10 fractions were dissolved, each in a specified volume of dichloromethane to give $1 \mathrm{mg} / \mathrm{ml}$ concentration and tested for their antimicrobial activities using Bacillus subtilis as test organism by disc-plate method. Among 10 fractions, fraction VI (49.8 mg) exhibited good activity and was purified by chromatography on Sephadex LH-20 (methanol) to obtain four fractions. The third fraction VIc was found to possess good antimicrobial activity while others have no or negligible activites. The active fraction VIc was further purified by chromatography on Sephadex LH-20 (acetone) resulting in two distinct fractions VIc.I (6 mg) and VIc.II (4.5 mg). Fraction VIc.I (1) had good antimicrobial activity $(100 \mu \mathrm{g} / \mathrm{ml})$ but negligible activity was observed with VIc.II. Compound $\mathbf{1}$ was found to be pure and was pale yellow solid.

The molecular formula of $\mathbf{1}$ was determined as $\mathrm{C}_{21} \mathrm{H}_{14} \mathrm{O}_{7}$ on the basis of the EI-MS $(70 \mathrm{eV})$, which gave a $\left(\left[\mathrm{M}^{+}\right], 40\right)$ ion at $\mathrm{m} / \mathrm{z} 378.1$ and elemental analysis (Calculated $\mathrm{C}$ : 66.67\%, H: $3.73 \%$ and O: $29.60 \%$; Obtained C: $66.68 \%, \mathrm{H}$ :

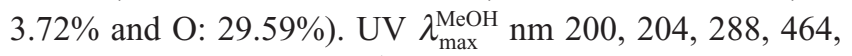
516. IR $v_{\max }(\mathrm{KBr}) \mathrm{cm}^{-1} 3422(\mathrm{OH}), 2924(\mathrm{CH}), 2854$ $(\mathrm{CH}), 1639(\mathrm{C}=\mathrm{O}), 1594(\mathrm{C}=\mathrm{C}), 1145(\mathrm{C}-\mathrm{O}), 1085$ (C-O).

${ }^{1}$ H-NMR ([D] $]$ DMSO, 300 MHz): $\delta=14.55$ (br. s, 1 H, $\mathrm{OH}$ ), 14.00 (br. s, $1 \mathrm{H}, \mathrm{OH}), 13.61$ (br. s, $1 \mathrm{H}, \mathrm{OH}), 7.48$ (s, 1 H, 11-H), 7.08 (s, $1 \mathrm{H}, 8-\mathrm{H}), 6.39$ (s, $1 \mathrm{H}, 4-\mathrm{H}), 6.32$ (br. s, $1 \mathrm{H}, \mathrm{OH}), 2.94$ (s, $\left.3 \mathrm{H}, \mathrm{CH}_{3}\right), 1.48$ (s, $3 \mathrm{H}, \mathrm{CH}_{3}$ ).

HMBC and HSQC Correlations: C-1: 12- $\mathrm{H}_{3}, 11-\mathrm{H}$; C-

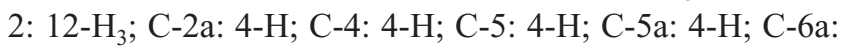
8-H; C-8: 8-H, 14-H ; C-9: 14- $\mathrm{H}_{3}$; C-9a: 11-H, 14- H3, 8$\mathrm{H}$; C-11: 11-H; C-11a: 12-H $\mathrm{H}_{3}$ C-11b: 11-H; C-13: 12- $\mathrm{H}_{3}$; C-14: $14-\mathrm{H}_{3}, 8-\mathrm{H}$.

The ${ }^{1} \mathrm{H}$ NMR spectrum of $\mathbf{1}$ showed broad singlets at $\delta=14.55,14.00$ and 13.61 with intensities of 1 proton each. These indicate the presence of 3 chelated hydroxyl

Table 2 Cytotoxic activities of 1-hydroxy-1-norresistomycin (1)

\begin{tabular}{|c|c|c|c|c|c|c|}
\hline \multirow{2}{*}{ Compound } & \multicolumn{3}{|c|}{ Cell line $\mathrm{HMO} 2$} & \multicolumn{3}{|c|}{ Cell line HePG2 } \\
\hline & $\mathrm{Gl}_{50}$ & TGI & $\mathrm{LC}_{50}$ & $\mathrm{GI}_{50}$ & TGI & $\mathrm{LC}_{50}$ \\
\hline 1 & 0.009 & 0.012 & 0.015 & 0.014 & 0.018 & 0.021 \\
\hline
\end{tabular}


groups in the molecule. In the aromatic region three singlets at $\delta=7.48,7.08 \& 6.39$ with relative intensity of one proton each were observed. This indicated the presence of three different protons. A broad singlet of one proton intensity appeared at $\delta=6.32$, this indicates the presence of hydroxyl group attached to alicyclic or cyclic compound. The singlet of three proton intensity peak at $\delta=2.94$ indicated the presence of a methyl group either on an aromatic ring or on heteroatom. Another peak at $\delta=1.48$ with three proton intensity also indicates the presence of another methyl group attached to either a cyclic or an aliphatic moiety.

The ${ }^{13} \mathrm{C}-\mathrm{NMR}$ spectrum exhibited two signals at $\delta=204.3 \& 184.7$ and these peaks indicated the presence of two carbonyl groups. In addition to this, 17 signals in the aromatic region and two signals in the aliphatic region were observed. The HMBC and HSQC data of $\mathbf{1}$ presented in Fig. 2 were crucial in determining the structure and are in full agreement with the structure. The important evidence of the structure comes from the HMBC correlation noticed for $\mathrm{C}-1$ carbon with the protons of the methyl group 12- $\mathrm{H}_{3}$
(1.48) and the proton at C-11 (7.48). The above spectral data suggest the structure for $\mathbf{1}$ as shown in Figs. 1 and 2. A comparison of ${ }^{13} \mathrm{C}-\mathrm{NMR}$ data of the pure $\mathbf{1}$ with that of the reported compound resistomycin $[14,15]$ was made (Table 1). The ${ }^{13} \mathrm{C}$-NMR data of the pure $\mathbf{1}$ is almost similar to resistomycin (2) except at $\mathrm{C}-1$ because of the presence of hydroxyl group.

The spectral information of the $\mathbf{1}$ was searched in different databases like Chapman and Hall, SciFinder, Beilstein and Antibase and no hints were observed in any of the databases. This indicated that 1-hydroxy-1norresistomycin (1), $\{1,3,5,7,10$-pentahydroxy-1,9-dimethyl$2 H$-benzo[cd] pyren-2,6(1H)-dion $\}$ is not reported so far (Figs. 1 and 2) and it is the only resistomycin analogue reported to date. The minimum inhibitory concentrations (MIC) of the $\mathbf{1}$ against different test organisms were determined by the broth dilution method (Table 3).

Acknowledgments The authors gratefully acknowledge Andhra University and University of Gottingen for providing necessary infrastructural facilities for carrying out the work.

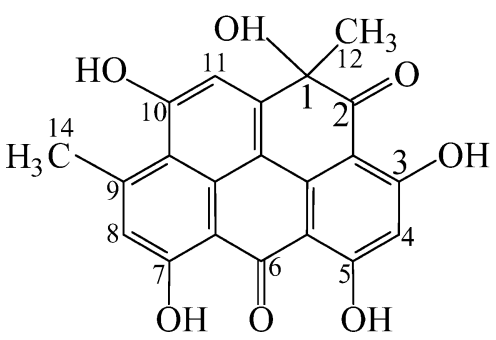

(1) 1-Hydroxy-1-norresistomycin<smiles></smiles>

(2) Resistomycin

Fig. 1 1-Hydroxy-1-norresistomycin (1) and resistomycin (2).

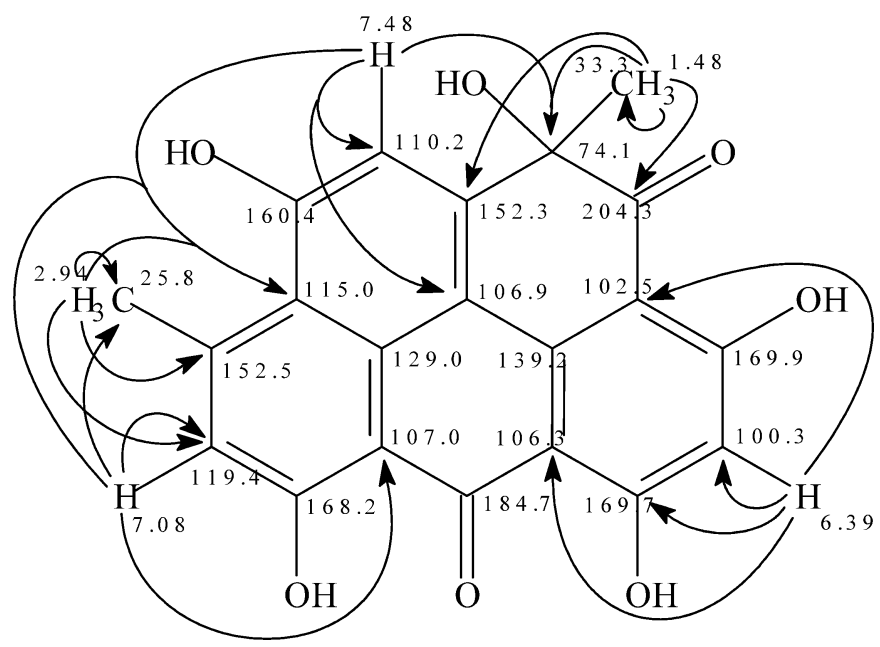

Fig. $2 \mathrm{CH}$-Correlations with $\mathrm{HMBC}$ and $\mathrm{HSQC}$ of $\mathbf{1}$ 
Table 3 Antimicrobial activities of 1-hydroxy-1norresistomycin (1)

\begin{tabular}{lc}
\hline \multicolumn{1}{c}{ Test organism } & MIC $(\mu \mathrm{g} / \mathrm{ml})$ \\
\hline Bacillus subtilis ATCC 6633 & 16 \\
Bacillus pumilus ATCC 19164 & 16 \\
Staphylococcus aureus ATCC 29213 & 64 \\
Escherichia coli ATCC 26 & 128 \\
Pseudomonas aeruginosa ATCC 27853 & $>128$ \\
Proteus vulgaris ATCC 6897 & $>128$ \\
\hline
\end{tabular}

\section{References}

1. Mukku VJRV, Speitling M, Laatsch H, Helmke E. Marine bacteria, XII: New butenolides from two marine streptomycetes. J Nat Prod 63: 1570-1572 (2000)

2. Cho KW, Lee HS, Rho JR, Shin J. New lactone-containing metabolites from a marine-derived bacterium of the genus Streptomyces. J Nat Prod 64: 664-667 (2001)

3. Sasaki T, Igarashi Y, Saito N, Furumai T. Watasemycins A and B, new antibiotics produced by Streptomyces sp. TPA0597. J Antibiot 55: 249-255 (2002)

4. Malet-Cascon L, Romero F, Espliego-Vanzquez, Gravlos D, Fernandez-Puentes JL. IB-00208, a new cytotoxic polycyclic xanthone produced by a Marine-derived Actinomadura. J Antibiot 56: 219-225 (2003)

5. Maskey RP, Helmke E, Laatsch H. Himalomycin A and B: Isolation and structure elucidation of new fridamycin type antibiotics from a marine Streptomyces isolate. J Antibiot 56: 942-949 (2003)
6. Feling RH. Salinosporamide A, a highly cytotoxic proteasome inhibitor from a novel microbial source, a marine bacterium of the genus salinospora. Angew Chem Int Ed Engl 42: 355-357 (2003)

7. Shirling EB, Gottlieb D. Methods for classification of Streptomyces species. Intern J Syst Bact 16: 313-340 (1966)

8. Waksman SA. (Ed.): Classification, identification and description of genera and species. In The Actinomycetes. Vol. II. pp. 328-334. Williams \& Wilkins Co., Baltimore (1961)

9. Arai T. $(E d$.): In Culture Media for Actinomycetes. The Society for Actinomycetes, Japan (1975)

10. Lechevalier HA, Lechevalier MP. A critical evaluation of the genera of aerobic actinomycetes. In The Actinomycetales, Prauser (Ed.): pp. 393-405, Jena, Gustav Fischer Verlag (1970)

11. Staneck JL, Roberts GD. Simplified approach to identification of aerobic actinomycetes by thin-layer chromatography. Appl Microbiol 28: 226-231 (1974)

12. Grever MR, Schepartz SA, Chabner BA. The National Cancer Institute: Cancer drug discovery and development program. Semin Oncol 19: 622-638 (1992)

13. Skehan P, Storeng R, Scudiero D, Monks A, McMahon J, Vistica D, Warren JT, Bokesch H, Kennedy S, Boyd MR. New colorimetric cytotoxicity assay for anticancer drug screening. J Nat Cancer Inst 82: 1107-1112 (1990)

14. Brockmann H, Mayler E, Schrempp K, Reiners F, Reschke T. Resistomycin, IV. Constitution of resistomycin. Chem Ber 102: 1224-1246 (1969)

15. Hofle G, Wolf $\mathrm{H}$. Isolation, ${ }^{13} \mathrm{C}-\mathrm{NMR}$ spectra, and biosynthesis of resistomycin and resistoflavin from Streptomyces griseoflavus B71 (Actinomycetales). Liebigs Ann Chem 835-843 (1983) 